It is intended that the Proceedings of the Conference shall be published in a single volume. There is no doubt that this will prove a worthy companion to the Proceedings of the first conference, held in 1938, and a valuable source of reference to all interested in rubber seience.

L. R. G. TreLOAR

R. F. NAYLOR

\section{NUTRITION OF ATHLETES}

A WHOLE-DAY meeting of the Nutrition Society on July 17 was devoted to the subject of the "Nutrition of Athletes". The first papers dealt with the physiology of muscular effort, and the meeting took a more practical turn later in the morning and in the afternoon session.

The meeting opened with a paper by Dr. Philip Eggleton of Edinburgh on "The Neuromuscular Mechanism". Physiological studies, he said, fall into three clear-cut categories. The first of these is the work on animals (including dog and man) which comprises measurements of work done, respiratory measurements, urine and blood analyses, nutrition studies and so on. The second category includes work on isolated muscles and nerves, which has been carried out mainly on cold-blooded animals because of the difficulty of using such preparations from mammals. Thirdly, there is work on the muscles of marine shell-fish. These last two methods have certain disadvantages in that it is difficult to apply the results obtained from them to the mammal, and particularly to the human being. Nevertheless, results from the three fields combine to produce a picture of the neuro-muscular machine which, according to the author, comes nearest to the physiologist's ideal-a description of physiological phenomena in terms of chemistry and physics - than has been achieved in respect of any branch of physiology, save perhaps the transport of gases by the blood.

Experiments in the first field have shown a simple relation between work done and food intake required ; and there is also considerable evidence that manual labourers do not choose to eat carbohydrates but prefer fat and protein. This preference for a high protein diet by both manual labourers and athletes may be a survival prrhaps of sympathetic magic ; yet it may have as a basis the fact that meat is a good source of some of the B complex of vitamins. The preference for fatty food is more understandable, since it is an economical source of energy.

Dr. Eggleton went on to discuss A. V. Hill's work on the oxygen consumption during exercise, and said that in Hill's experiments the consumption of oxygen was about 4 litres a minute for men engaged in running at a pace which did not give them undue respiratory distress. However, these experiments only lasted for minutes, and Eggleton pointed out that the heart cannot pump 4 litres of oxygen into the body indefinitely ; if the exercise has to be maintained for some time, an oxygen consumption of 1 litre per minute is nearer the upper limit. In this connexion Dr. Eggleton remarked that an athlete can build up an oxygen debt for events such as the 100-yd. sprint, and that in this event the rate of output of energy of the runner is 10-13 horse-power, which corresponds to an oxygen intake of 23 litres a minute-six times anything the heart can achieve. This debt is financed partly by the breakdown of glycogen to lactic acid and partly by the reserve of non-oxidative energy represented by the creatin phosphate content of muscle.

Dr. Eggleton discussed some of the aspects of the evolution of the neuro-muscular mechanism, and pointed out that one of the differences between invertebrate and vertebrate muscle is the presence of arginine in the muscles of the former and of creatine in muscles of the latter. Also vertebrate muscles contain considerable amounts of two di-peptides$\beta$-alanylhistidine and $\beta$-alanyl-methyl-histidinewhich are not present in invertebrate muscle.

In conclusion, Dr. Eggleton commented upon the apparent increasing athletic abilities of the human race, which he felt were more apparent than real, and upon the view that the decreased performances of British athletes recently is due to the changes in diet and habits engendered by the War, a problem which he felt should be left to later speakers.

Dr. Dorothy Needham spoke on chemical aspects of chemical contraction. In this field, Dr. Needham said that two lines of work, followed independently for about half a century, had only recently come together. One of these was the nature of the muscle machine, and the other was the nature of the essential fuel. Dr. Needham discussed the early work of Fletcher and Hopkins and of Meyerhof on the energy liberated by the formation of lactic acid in muscle, and of Lundsgaard's work on creatine-phosphate breakdown as a source of energy. Lohman's work in 1934, she said, suggested that adenosine triphosphate hydrolysis supplied the first energy-yielding reaction in muscular contraction.

The old idea that lactic acid production is an inevitable accompaniment of contraction has had to be discarded since it has been shown that much work can go on without any lactic acid formation. The most important constituent of the muscle machinery is the protein, and the modern phase began with the work of Edsall and von Muralt in 1930. Solutions of myosin showed the property of double refraction in flow, and this suggested some relation with the anisotropic bands of myo-fibrils. It appears that the contractile fibrils of muscle consist of polypeptide chains of myosin showing the $\alpha$-fold, and owe their elasticity and contractility to their power of straightening out to the fully extended chain or folding up still further. The link between the machinery and the fuel comes from the observation that myosin has adenosine triphosphatase activity, so that myosin is not only the chief structural entity of muscle but is also the enzyme catalysing the chemical processes which lead to its own contraction. Szent-Györgyi has shown that another fibrous protein, 'actin', can be extracted from muscle, and that actin and myosin may unite to form fibrils of much greater length; this compound of the two proteins is called actomyosin.

It seems possible that some of the symptoms of fatigue may be due to the breaking of inter-molecular links which hold the partly folded polypeptide chains in place. If contraction is too severe and prolonged, too great a distortion may take place and unusual breaking of links or the formation of new and inconvenient ones may take place.

There are at the moment two main views on muscular contraction. One is that the contracting fibrils are made up of actomyosin. If adenosine triphosphate comes into contact with actomyosin fibrils, there is a rapid change of the protein with loss of water. Szent-Györgyi regards this as synonymous with contraction; on the other hand, Astbury has sug. gested that in resting muscle the fibrils are made 
more rigid and stable by combination in parts with a parallel actin-system, and that-upon stimulation this combination is loosened by the action of adenosine triphosphate. When this happens the myosin can take up a shortened form of folding.

Group Captain C. A. Rumball described the practical uses to which investigations on the neuromuscular mechanism have been put in the choice of air-crews by the R.A.F. Pulse-rates while sitting, standing and under stress gave useful information. Diastolic blood pressures of more than $90 \mathrm{~mm}$. were not acceptable, though up to $90 \mathrm{~mm}$. was. However, it was pointed out that fifty-five marathon runners examined in 1909 had an average diastolic pressure of $93 \mathrm{~mm}$. of mercury. One test which gave information of considerable value was that designed by Flack in 1920, in which a subject was asked to sustain a $40-\mathrm{mm}$. column of mercury in a U-tube manometer by a single expiration for as long as possible, and the pulse response examined. There are four main types of pulse response to this test; but only two of them, namely, a rapid and sustained rise to 10 or more beats per 5-sec. interval and a rapid rise followed by an abrupt fall to a low figure, indicated low functional efficiency.

Nutritional aspects of muscular activity were introduced by Dr. G. H. Bourne in a paper entitled "Vitamins and Muscular Exercise". Dr. Bourne pointed out that vitamins of the B complex play an important part in the reaction chains concerned with carbohydrate metabolism, and the demand for them might be expected to be increased in muscular exercise. A figure of fifteen times the normal requirement for vitamin $B$ in severe exercise has been quoted. This would mean a daily intake of $22.5 \mathrm{mgm}$. (based on a normal daily requirement of $1-5 \mathrm{mgm}$. of vitamin $B_{1}$ ). To obtain this amount of vitamin $B_{1}$, one would need to consume $6 \frac{1}{2}$ kilos of National wheatmeal bread, $\frac{3}{4}$ kilo of commercial wheat germ or $90 \mathrm{gm}$. of dried brewers' yeast. One should consider, therefore, if these greatly increased demands for vitamins of the B complex do exist, and if they do, whether it would be possible for an athlete to obtain them from natural foods, with the possible exception of dried yeast. Perhaps, then, an athlete's performance is limited by his vitamin B complex intake, and this is itself limited by the amount of natural food he can eat. The consumption of quantities of meat, liver, eggs, etc., by athletes may be related not to the protein content of these foods, but to the relatively high amounts of various members of the vitamin B complex they contain.

If supplementation of athletes' diets is undertaken, it should be remembered that there is some evidence that certain vitamins may have a supra-physiological or pharmacodynamical action, which may or may not be related to their normal nutritional function. Inspection of the literature on the effects of supplementing the diet with various vitamins of the $B$ complex shows no uniformity of results; but on the average there does seem to be a bias in favour of the beneficial effect of these vitamins on muscular exercise.

Attempts to show that extra doses of vitamin $\mathbf{C}$ increased resistance to fatigue have also been equivocal ; but there seemed to be some evidence in favour of its use.

There is little doubt that deficiency of most vitamins seriously affects muscular effort; but the difficulty is in deciding just at what level of intake deficiency exists.
Dr. Boume felt that the subject of nutrition of athletes, with its obsession with calories and proteins, is lagging considerably behind modern advances in nutritional science.

In the afternoon, Sir Adolphe Abrahams asked what indication there was for a high calorie diet for athletes, what foodstuffs should predominate in it, and thirdly, what part, if any, alcohol should play in the diet of athletes?

On the question of calories, Sir Adolphe said that the figures published of the calorie intake of athletes at the Berlin Olympiad in 1936, which were said to have been compiled from observations on 4,700 competitors, were extraordinary. They quoted a daily average intake of $800 \mathrm{gm}$. of meat, $150 \mathrm{gm}$. of

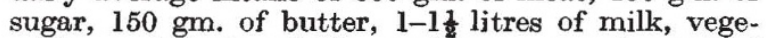
tables and fruit ad lib., making a grand total of 7,300 calories. Such an intake is really equivalent to the requirements of a $24-\mathrm{hr}$. walking race, or daily violent physical exercise of six hours duration. In fact, no athlete in training undertakes six hours violent physical exercise a day. Most athletes visit the track twice a day. The sprinter does a few bursts from the start and a run through of $150 \mathrm{yd}$. each time, and few of even the long-distance men do really hard work during their training period. Events such as the annual Oxford and Cambridge boat race only use up about 500 calories per man. Athletes, therefore, do not need vast quantities of food; but a generous diet is desirable from a psychological point of view.

Discussing the role of meat in the diet, Sir Adolphe pointed out that athletes who claimed to be vegetarians invariably consumed milk, cheese and eggs, containing animal protein. He felt that extra sugar is not of particular benefit to athletes. The men of to-day are not better physically than the men of fifty years ago, and Sir Adolphe felt that the explana. tion of improved records is partly due to improved technique and partly to the increasing growth of the cult of athleticism.

The final paper of the day was given by Dr. Nevil Leyton on "Some Practical Aspects of the Training of Athletes". Dr. Leyton made the important point of the difference in individual calorie requirements for the performance of the same task, and the difference in the times before events that individual athletes require to eat. The actual calories for the Oxford and Cambridge boat race may be as much as 600 per man; this figure may be compared with that for a Marathon race, when 2,000 calories may be used. A five-set tennis match may use 1,200 calories. In addition, the body may continue to expend energy at a higher rate than normal for 24-48 hours after the event. A good training diet should nourish the athlete adequately during this period and should include fruit and vegetables, the function of these being partly to provide vitamins. Some consideration must also be given to the possibility of assisting the athlete during the contest. A 20-min. all-out effort uses about an ounce of sugar. So a marathon runner may use nearly $5 \mathrm{oz}$. in a race. Four ounces of sugar may be absorbed from the gut in about two hours. Some benefit should accrue to performance if an athlete is given sugar an hour or two before an event. Even if calories can be provided in sufficient amounts, it is often difficult in Britain to-day to provide an athlete with just the food he feels he wants, and this may have an adverse psychological effect.

The day's discussions were ably summed up by the chairman, Prof. J. R. Marrack. 